\title{
Mapping of Geological-Geotechnical Risk of Mass Movement in an Urban Area in Rio Piracicaba, MG, Brazil
}

\author{
L.E. Assis, E.A.G. Marques, C.A. Lima, S.J.M.C. Menezes, L.A. Roque
}

\begin{abstract}
The objective of this study is to create a geological-geotechnical risk map of mass movement for an urban perimeter of Rio Piracicaba city, state of Minas Gerais, MG, Brazil, by applying the methodology proposed by the Brazilian Ministry of Cities. Four neighborhoods were evaluated through works conducted in the field and with the aid of a GIS fed with aerial images obtained from an Unmanned Aerial Vehicle (UAV). In these neighborhoods, 29 points were categorized as risk-points, and 14 risk areas were delimited and hierarchized. Despite being considered a subjective evaluation, the methodology used is a simple and efficient qualitative method, which can contribute significantly to the preliminary identification of areas under risk of mass movements, indicating the nature of the predisposing factors. The areas classified as high-risk present significant physical and environmental problems, mainly due to non-compliance with current legislation regarding urban planning and land use. The outcomes of these surveys are valuable tools that will facilitate the planning and management of land use and occupation in the municipality.
\end{abstract}

Keywords: geotechnical cartography, geological-geotechnical risk, gis, mass movements, risk hierarchizing, UAV.

\section{Introduction}

Gravitational mass movements are important surface terrestrial phenomena and constitute a natural evolution of the slopes (Wolle, 1988). This type of events are related to the loss of shear strength of soils and/or rocks along a failure plane, intensified by the interference of other factors such as water, ice and air presence and slope (Bigarella \& Passos, 2003). However, this phenomenon is no longer considered as only "natural", due to the numerous processes of anthropic intervention by the absence of planning and by degradation of the environment.

Disasters are considered inevitable and are directly related to the probability, intensity, danger and susceptibility of the factors involved, and which are related to environmental, social and economic conditions. However, they can be minimized through preventive actions, with the purpose of safeguarding communities at risk, based on monitoring and territorial planning (UNISRD, 2004). The International Decade for Natural Disaster Reduction (IDNDR) considers risk as the combination of the probability of a given event to occur and its likely negative consequences (UNISRD, 2009).

According to Tominaga (2007), the term "area of risk" is increasingly incorporated into the vocabulary of the Brazilian population, since accidents involving mass movements and floods during the rainy season have intensified and affected many communities that occupy slopes and urban areas with deficient infrastructure.
Vieira (2000) differentiates risk points from risk areas, by considering that risk points are imminent situations, which must be linked to a specific building or locality. Risk areas comprise situations that cover a larger proportion of space, with irregular shapes and sizes and encompass risk points that can, eventually, have different risk class.

The human actions that most interfere in the triggering of mass movements on slopes are related to deforestation, lack of drainage direction, inefficient natural drainages, cuts and landfill performed without technical support, poorly implemented engineering works, excavations and waste dump (Araújo, 2004).

Due to the numerous episodes of natural disasters recorded in recent years, mainly related to urban occupation of places susceptible to geological risks, Brazilian authorities were encouraged to take risk management measures. Based on interventionist practices and policies, these measures were established with the aim of contributing to the monitoring and a more ordered growth of the urban perimeter.

The Brazilian National Policy on Protection and Civil Defense - PNPDEC, created by Federal Law 12.608 / 2012 addresses, in its priority concepts, the necessity of mapping and preventive actions for the reduction of disasters. The purpose of this law is to enable municipalities susceptible to these types of events to produce a preventive and orderly land use plan (Diniz, 2012).

Laís Emily de Assis, M.Sc., D.Sc. Student, Universidade Federal de Viçosa, Viçosa, MG, Brazil. e-mail: laismily9@gmail.com.

Eduardo Antonio Gomes Marques, D.Sc., Full Professor, Universidade Federal de Viçosa, Viçosa, MG, Brazil. e-mail: emarques@ufv.br.

Cleverson Alves de Lima, D.Sc., Associate Professor, Universidade Estadual de Santa Cruz, Ilhéus, BA, Brazil. e-mail: clalima@uesc.br.

Sady Junior Martins da Costa de Menezes, D.Sc., Associate Professor, Universidade Federal Rural do Rio de Janeiro, Três Rios, Rio de Janeiro, Brazil. e-mail: sadymenezes@yahoo.com.br.

Leandro Antônio Roque, M.Sc., Universidade Federal de Viçosa, Viçosa, MG, Brazil. e-mail: leandroroque1@ hotmail.com.

Submitted on March 13, 2019; Final Acceptance on November 6, 2019; Discussion open until August 31, 2020.

DOI: $10.28927 /$ SR.431057 
Among the changes in the regulatory framework proposed by PNPDEC, the Cities Statute designated by Federal Law 10.257 / 2001, which deals with urban policy guidelines, has undergone various alterations. These new obligations demand that all municipalities must present their susceptibilities to natural disasters through geotechnical charts and/or maps and identify and monitor major risk areas (occupied or not) (IPT, 2015).

Based on risk management works carried out by the Technological Research Institute of São Paulo (IPT), the Ministry of Cities has been supporting initiatives related to the monitoring and prevention of risks in precarious settlements in municipalities, by conducting direct actions and providing training through federal agencies (Brazil, 2007). According to Marques et al. (2011), this methodology is currently considered one of the most used for risk assessment in Brazil.

As observed by Marchiori-Faria et al. (2005), risk mapping performed to serve as a base for Civil Defense is considered one of the main forms of technical support provided to municipalities for their management and contingency planning. The identification and qualification of risks, based on field assessments, enables a rapid implementation of mitigating actions in areas considered susceptible to instabilities.

In recent years, along with several mapping methods, the use of tools such as remote sensing, aerial photogrammetry and other geotechnologies are considered fundamental instruments for mass movement risk management. The evaluation of risk scenarios based on the use of geotechnologies to acquire cartographic data has become a fundamental tool for the understanding of threats, for promoting an integrated management of contingency plans and for supporting management of disaster forecasting.

According to studies by Akgun (2012), Saito et al. (2015) and Shahabi \& Hashim (2015), GIS is a necessary but still little explored technology in the recording of vulnerable communities and informal settlements for risk mapping. GIS is considered a satisfactory technique because it allows, through coordinates measured by GPS (Global Positioning System), to record points and to correlate them with images in GIS environments, acting as an aid in the estimation of monitoring and alert.

In this context, the present study aims to identify the processes responsible for the geological-geotechnical risk of mass movement in an urban perimeter composed by 4 neighborhoods in the city of Rio Piracicaba, MG, Brazil, by applying the methodology proposed by the Ministry of Cities, Brazil (2007). The focus was to identify points and areas based on field surveys, supported by a qualitative approach and field mapping. The identification was performed by using orthorectified aerial images obtained through the use of an UAV.

Risk assessment is a fundamental process for the prevention and monitoring of the study areas as they show an urban expansion involving irregular constructions, in a steep terrain and under unfavorable geological and geotechnical conditions. Even with these unfavorable characteristics, the majority of these risk areas do not have any registry in the municipal civil defense, as it will be demonstrated.

\section{Materials and Methods}

\subsection{Characteristics of the study area}

According to data from IBGE (2010) the municipality of Rio Piracicaba, located in the central part of the Minas Gerais State, has a total area of $373.4 \mathrm{~km}^{2}$ and an estimated population of 14,149 inhabitants (Fig. 1).

Being part of the region known as Iron Quadrangle, the municipality is located mostly in a granite-gneiss domain and presents an extensive lithostratigraphic registry, and a northeast structural direction.

More recent surveys carried out by CPRM (2014) have shown that the main lithotypes found in Rio Piracicaba area are amphibolites, orthogneisses, shale and banded iron formations, presenting materials varying from very weathered to sound rock. Some other factors stimulate the occurrence of mass movements, such as: slope, thick weathering mantle, clay-silt rich soils, detrital cover ("canga" deposits) and presence of transition areas with soil-rock contacts and talus deposits at the foot of the slope. Climate is also a controlling factor, as there is a rainfall concentration, mainly between the months of November and January. According to Köppen classification, climate of Rio Piracicaba can be classified as Cwa, mesothermic climate with hot and rainy summers and dry winters, and average precipitation of $1462 \mathrm{~mm}$ (CPRM, 2010).

According to CETEC (1983) there are two predominant geomorphological units in the municipality, the Iron Quadrangle and the Dissected Plateaus, the Piracicaba river being the topographic divider between these units.

\subsection{Modeling of the land of the municipality of Rio Piracicaba, MG, based on images generated by an UAV}

A Sensefly Swinglet CAM Unmanned Aerial Vehicle (UAV) was used to survey the study area (Fig. 2). The UAV features a calibrated 12 MP Canon IXUS220HS RGB onboard camera that allows 7 to $30 \mathrm{~cm} /$ pixel spatial resolution (GSD) images. Its navigation system has sensors and GPS receivers with flight autonomy of up to $30 \mathrm{~min}$ and it is able to fly at a cruising speed of up to $36 \mathrm{~km} / \mathrm{h}$ and resistance to winds of $5 \mathrm{~m} / \mathrm{s}^{-1}$.

A Garmin 60CSx GPS, with positioning accuracy $\leq 10.0 \mathrm{~m}$, was used to collect the points. The takeoff area of the UAV was set at Point 1, from where the flight plan was executed (Fig. 3). The eMotion 2 software was used to control the UAV; it allows telemetry connection to the computer and transmits frequent correction signals, besides 

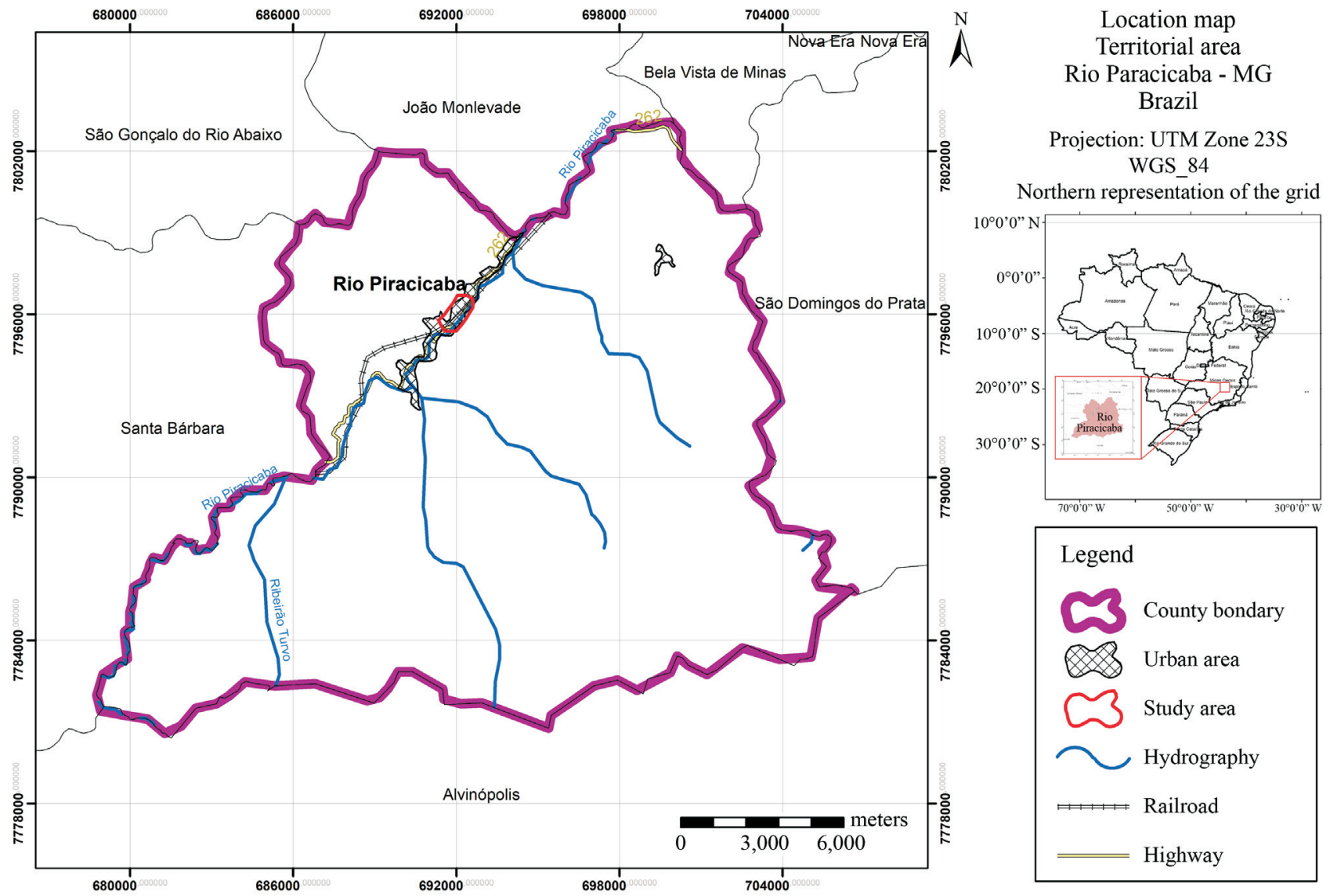

Location map Rio Paracicaba - MG n: UTM Zone 23

WGS 84

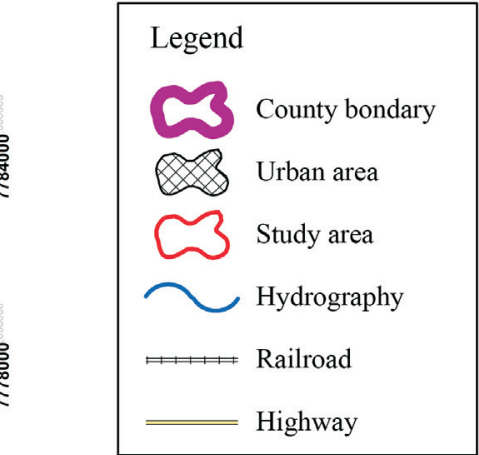

Figure 1 - Location Map of the Municipality of Rio Piracicaba, MG, Brazil.

(a)

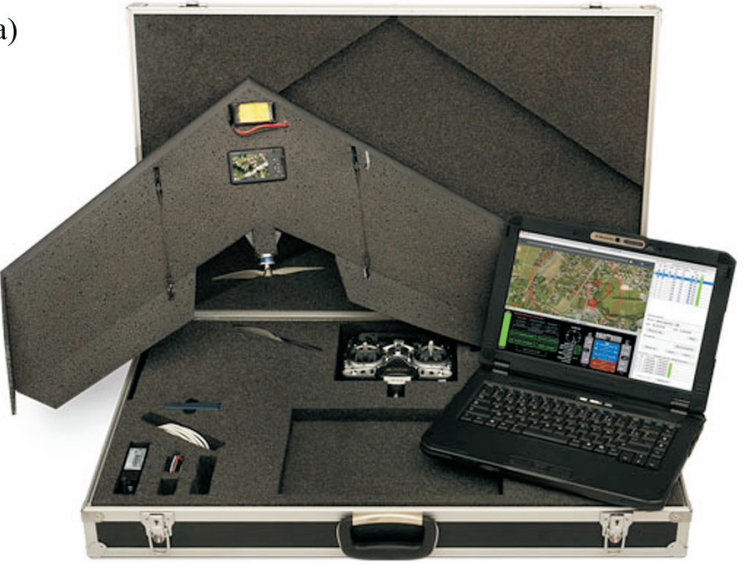

(b)

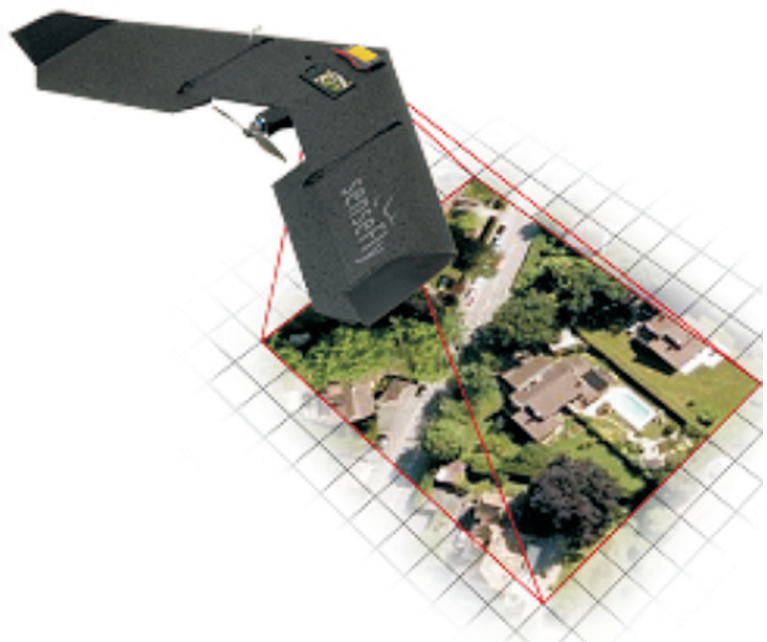

Figure 2 - UAV - Swinglet Cam Sensefly (Santiago \& Cintra, 2015).

providing improvements in the ground/air resolution, increasing the safety of taking aerial photos.

The flight was carried out in favorable weather conditions to obtain data, with winds within the tolerance stated by UAV specifications and absence of precipitation and cloudiness. The survey covered an area of 124.06 ha and allowed capture of overlapping images (overlay) of $400 \mathrm{~m}$ x $300 \mathrm{~m}$, for later use and preparation of cartographic digital bases. The processing was carried out at the Geotechnology Laboratory of Três Rios (GEO3R) Institute of Federal Rural University of Rio de Janeiro. The computational programs used in the procedures were: 


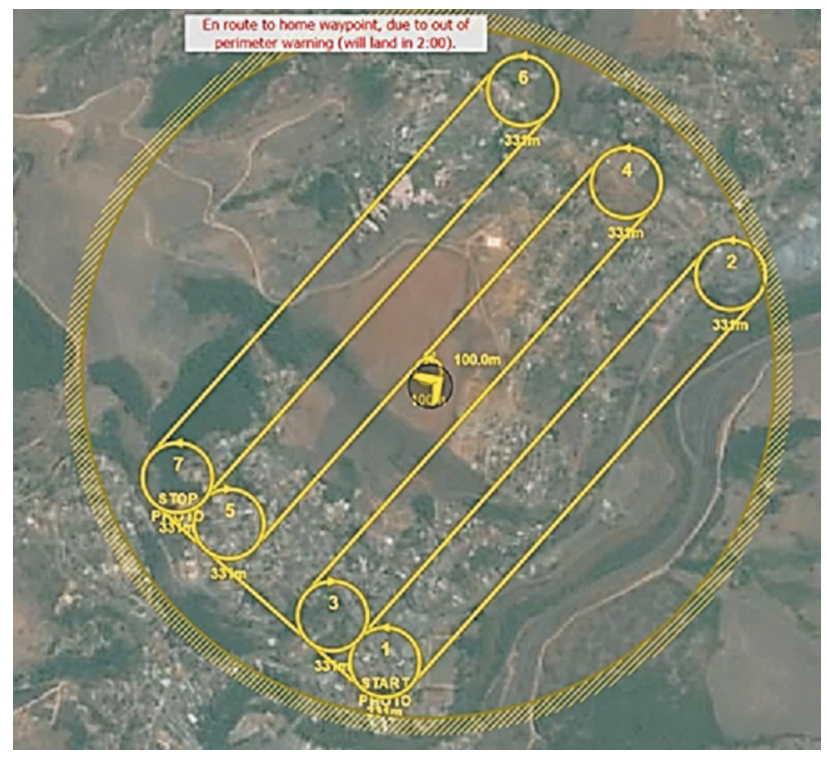

Figure 3 - Flight plan elaborated for the aerophotogrammetry of the study area. (Geographic Coordinate: Latitude: 691744,632; Longitude: 7796284,803).

Postflight Terra ${ }^{\circledR}$ 3D, Pix4UAV® Desktop and ArcGis ${ }^{\circledR}$ ESRI.

\subsection{Modeling of thematic maps}

Modeling of the thematic maps was performed at the Civil Engineering Department of the Federal University of Viçosa. The software ArcGis ${ }^{\circledR}$ 10.3.1 ESRI (Environmental Systems Research Institute) was used for the production of the following cartographic data:

- Terrain Modeling;

- Delimitation of study area and hydrography, complemented by identified drainage;

- Digital elevation model (DEM): made using Arctoolbox software, Topo to Raster interpolator, with the curves generated by the software Raster Surface - Contour as input data;

- Declivity: drawn from the Digital Elevation Model (DEM) and the level curves (Topographical Map) by way of geoprocessing in Slope software (3D analyst tool). The gradient (slope) analysis was subdivided into six classes, according to EMBRAPA (1979): 0-3 \% (wavy), $8-20 \%$ (gentle wavy), 20-45\% (wavy strong), 45-75\% (mountainous), > $75 \%$ (steep)

- Interfaces with 3D thematic map, using ArcScene.

All the outcomes were organized from the orthomosaic obtained by the UAV survey, which contributed to the geomorphological analysis and characterization of the study area.

\subsection{Processing and obtaining the database by the UAV}

For the generation of the database collected from the flight and the junction of the 41 aerial photos, georeferencing and association of the geographic coordinates were performed using the Datum WGS84 UTM zone 23S system. Postflight Terra ${ }^{\circledR}$ 3D system and Pix4UAV® Desktop softwares were used to process the images and acquire the Orthomosaic and Digital Surface Model (DSM) (Fig. 4).

The data processed allowed to generate a GSD (Ground Sampling Distance) with 14 to $18 \mathrm{~cm} /$ pixel spatial resolution for the image-surveyed area. These data were essential for the production of the digital terrain model and contributed for the assessment of a good representation of the study area.

The presentation of the three-dimensional perspective (3D) (Fig. 5) was obtained by ArcGis ${ }^{\circledR}$ ESRI software in the ArcScene 10.3.1 extension. This information was an essential base for the modeling and for the understanding of events in the area.

\subsection{Application of the methodology of the Ministry of Cities - Geological-geotechnical risk qualification}

To determine the study area, meetings were held with the Civil Defense department of Rio Piracicaba Municipal-

(a)

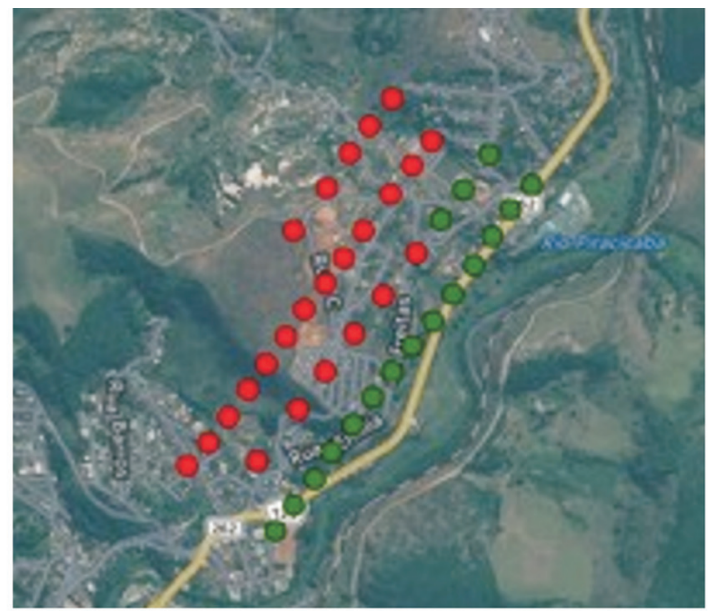

(b)

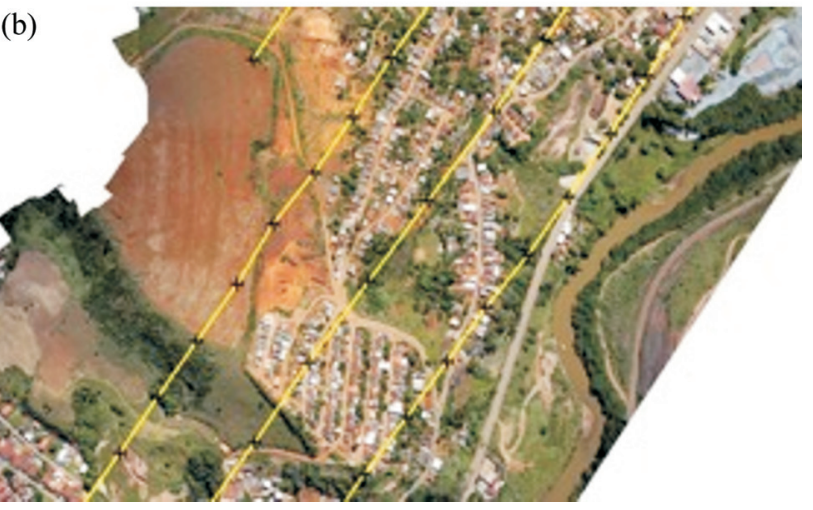

Figure 4 - (a) Element of Pix 4 UAV® Desktop Software in the study area after taking pictures (Geographic Coordinate: Latitude: 691744,632; Longitude: 7796284,803). (b) Component part of the processed Orthophoto showing the flight paths (trajectory) of the UAV over the studied area (Geographic Coordinate: Latitude: 691744,632; Longitude: 7796284,803). 


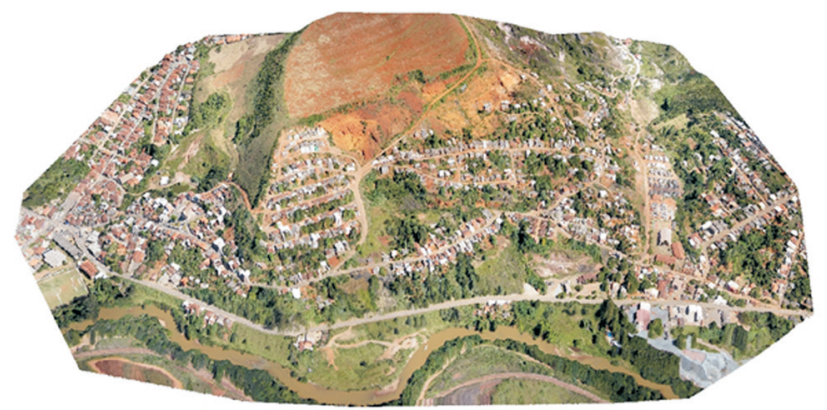

Figure 5 - Three-dimensional perspective (3D) of the study area obtained with ArcScene®, version 10.3.1 (Geographic Coordinate: Minimum Latitude: 691341,000000, Maximum Latitude: 692625,813950; Minimum Longitude: 7795380,931400, Maximum Longitude: 7796856,871180) (Scale in 2D: XY Scale 1:7.000, Z Scale Elevation Factor: 1,5 ArcScene $\left.{ }^{\circledR}\right)$.

ity, and were supported by its historical collection on land use and occupation, landslide occurrences and social aspects. Geological-geotechnical mapping involved the complete evaluation of four neighborhoods (Córrego São Miguel, Padre Levy Housing Complex, Bom Jesus, Nossa Senhora da Conceição) in which the points and areas of geological-geotechnical risk associated with physical environment information were registered and georeferenced.

Points were collected by means of field surveys carried out in every street of the four evaluated neighborhoods using a GARMIN 60CSx GPS and photographic records. In these surveys, two different risk situations were identified and named: 1) current risk (situations of geological risks present in the urban area), and 2) potential risk (susceptibility in unoccupied areas). In the identification and mapping stage, geological/geomorphological diagnostic and land uses identification were performed, in which certain specific conditions were considered (see Table 1), for the classification of current and/or potential risk to mass movements within the study area.

The delimitation of the areas of risk (zoning) was carried out in the field through sectorization on the local cartographic base and the information of the previously identified risk points. The degree of risk for a given element was evaluated individually, mainly considering the typologies of the constructions for each sector and/or demarcated households, as well as its vulnerability to mass impact, in addition to the other observations related to the geologi-

Table 1 - Aspects for the classification of current/potential risk of mass movements in the study area. Adapted from Souza (2015).

\begin{tabular}{|c|c|c|}
\hline Geological/geomorphological diagnosis & Use and occupation diagnosis & Identification of the main triggers \\
\hline \multirow{2}{*}{$\begin{array}{l}\text {-Local geology (main lithotypes, struc- } \\
\text { tures, orientation of minerals, elements of } \\
\text { discontinuity) }\end{array}$} & $\begin{array}{l}\text { - Constructive standard of residences } \\
\text { (cracks etc.) }\end{array}$ & $\begin{array}{l}\text { - Disposal of trash and debris material on the } \\
\text { slope }\end{array}$ \\
\hline & - Poorly located constructions & $\begin{array}{l}\text { - Drainage; Leakage of tubing/ Releasing of } \\
\text { wastewater on the surface / Sanitary septic } \\
\text { tanks }\end{array}$ \\
\hline \multirow{3}{*}{$\begin{array}{l}\text { - Terrain (altimetry, declivities and orienta- } \\
\text { tions of slopes), identification of main trig- } \\
\text { gers related to hydrological-climatic } \\
\text { processes, natural changes in the inclination } \\
\text { of layers }\end{array}$} & $\begin{array}{l}\text { - Inefficient/nonexistent drainage sys- } \\
\text { tem }\end{array}$ & - Identification of erosive features \\
\hline & - Withdrawal of protection surface & - Mass movement scars \\
\hline & - Removal of vegetation cover & $\begin{array}{l}\text { - Cuts with inappropriate heights and inclina- } \\
\text { tions; Released landfills; Execution of defi- } \\
\text { cient landfills. }\end{array}$ \\
\hline
\end{tabular}

Table 2 - Risk hierarchy criteria (adapted from Brazil (2007) by Roque (2013).

\section{Degree of probability Description}

(R0) No risk 1. The predisposing geological-geotechnical conditions (slope, type of terrain, etc.) and the level of intervention in the sector are of no potential for the development of landslides and undermining.

2. Sign/feature/evidence(s) of instability is/are not observed. There is no evidence of development of drainage-margin or slope instability.

3. If existing conditions are maintained, destructive events are not expected to occur in the period of a normal rainy season.

(R1) Low 1. The predisposing geological-geotechnical conditions (slope, type of terrain, etc.) and the level of intervention in the sector are of low potential for the development of landslides and undermining.

2. There are of some signs/features/evidence of instability (slopes and drainage margins), although incipient. Process of instability at an early stage of development. 
Table 2 - Cont.

(R2) Medium

3. If the existing conditions are maintained, there is a low possibility of destructive events occurring during episodes of intense and prolonged rains in a rainy season.

1. The predisposing geological-geotechnical conditions (slope, type of terrain, etc.) and the level of intervention in the sector are of medium potential for the development of landslides and undermining.

2. There are significant signs/features/evidence of instability (cracks in the ground, denudational landforms in slopes, etc.). The instability process is ongoing; however, it is still possible to monitor its evolution.

3. If the existing conditions are maintained, it is quite possible that destructive events occur during episodes of intense and prolonged rains in the period elapsed by the rainy season.

(R3) High

1. The predisposing geological-geotechnical conditions (slope, type of terrain, etc.) and the level of intervention in the sector are of high potential for the development of landslides and undermining.

2. There are signs/features/evidence of instability (cracks in the ground, denudational landforms in slopes, cracks in dwellings or retaining walls, tilted trees/poles, landslide scars, erosive features, proximity of dwellings in relation to banks of streams, etc.) and they are expressive and observed in great number or magnitude. Instability process at an advanced development stage.

3. If the existing conditions are maintained, it is very likely that destructive events will occur during episodes of intense and prolonged rains in the period elapsed by the rainy season.

cal-geotechnical conditions and evidence of instability, according to Brazil (2007).

The data sheet used for risk mapping, with the results of the geological-geotechnical fieldwork evaluations, was adapted by Roque (2013) from the methodology proposed by the Ministry of Cities (Brazil, 2007) (see Table 2). Its main benefit is to standardize the criteria used to define the degree of risk of mass movements in the study area. The hi- erarchy of the degree of risk was based on the judgment and experience of the technical team (qualitatively), responsible for the survey. For zoning risk, a four-level probability hierarchy was set, adapted from the Ministry of Cities classification: (R0) No risk, (R1) Low Risk, (R2) Medium Risk and (R3) High Risk, being R3 considered as needing immediate intervention.

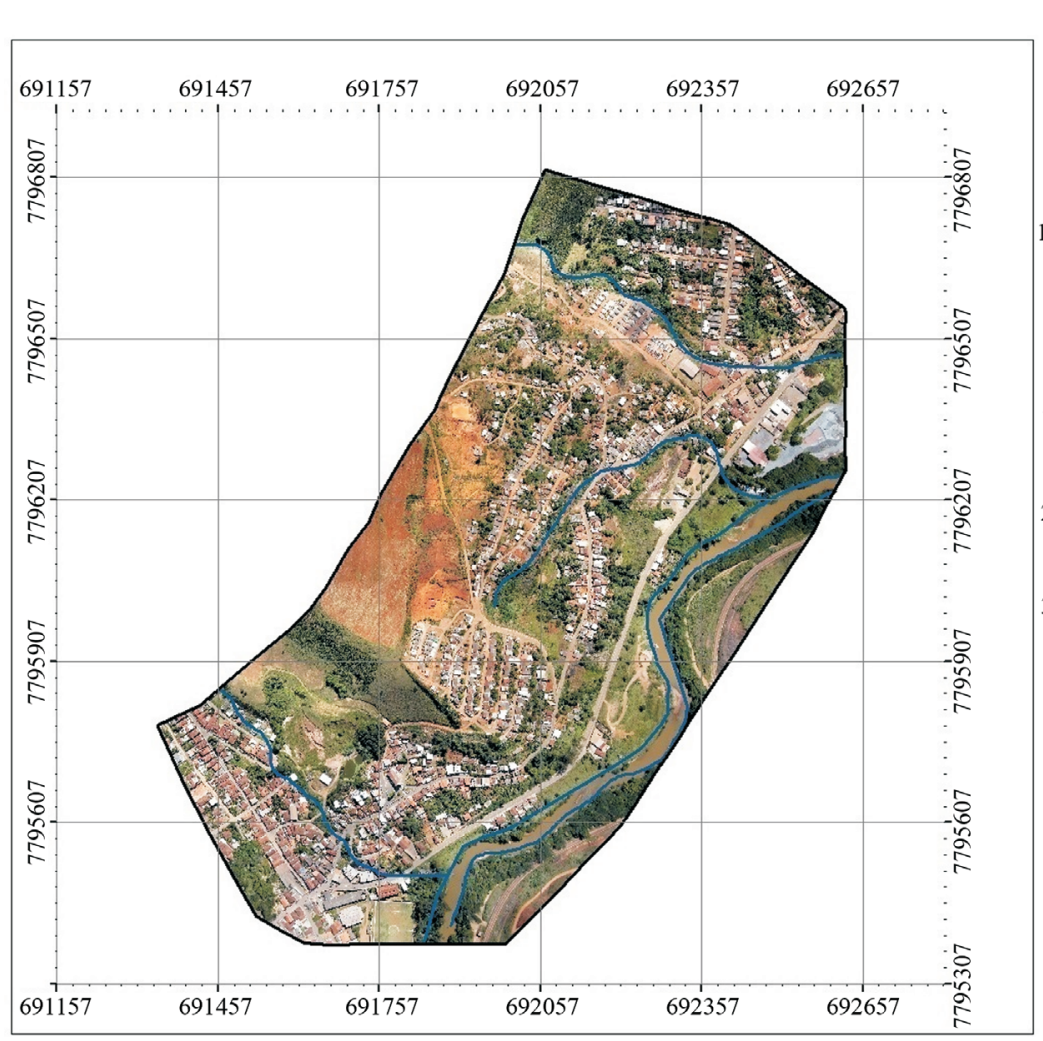

N Map study area

A Rio Piracicaba (MG), Brazil

Projection: UTM zone 23S WGS 84

Northenr representation of the grid

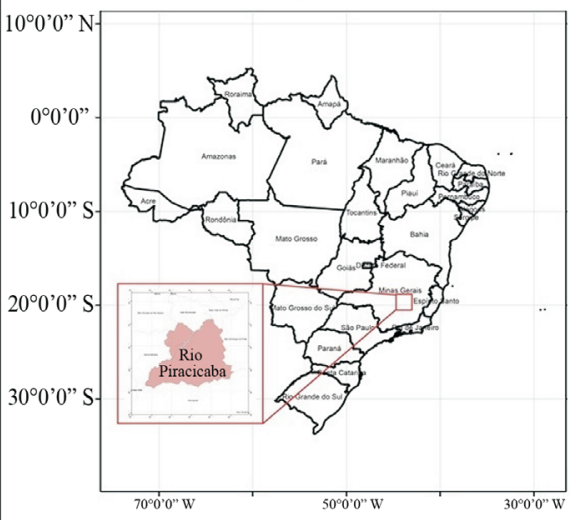

Legend

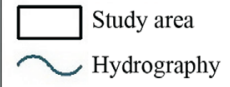

7,000

$500 \quad 1000$

Figure 6 - Map of the study area in Rio Piracicaba, MG. 
The points and areas mapped and the delimitation of risk sectors were plotted and organized in an RGB (3-2-1) orthomosaic (Fig. 6) obtained from the aerial photogrammetric survey by the Unmanned Aerial Vehicle (UAV) and processed with Postflight Terra ${ }^{\circledR}$ 3D and Pix4UAV® Desktop systems. This image has enabled to build the cartographic base in the GIS environment. This cartographic base, with scales varying from 1:7.000 to 1:800, aided the verification of points and the creation of the polygons of the georeferenced areas. The software used for the generation of scenarios and sectorization of risk was the ArcGis ${ }^{\circledR}$ 10.3.1, developed by ESRI (Environmental Systems Research Institute).

\section{Results and Discussion}

The classification of the degree of risk of the areas and points that were mapped in the four evaluated neighborhoods are shown in Table 3 and on the map presented in Fig. 7. As stated, the hierarchy was classified based on the type of use, pattern of settlement and other triggering aspects observed on the ground, in accordance with the methodology of the Ministry of Cities. Moreover, classification also took into account the diagnosis of the physical characteristics integrated into the digital cartographic data of the study area in GIS environment (digital terrain model, altimetry, slope, land use and occupation, and mass movement scars).

Table 3 - Number of points and areas by neighborhoods.

\begin{tabular}{|c|c|c|c|c|c|c|c|c|c|}
\hline \multirow[t]{2}{*}{ Neighborhoods } & \multicolumn{3}{|c|}{ Points of risk } & \multicolumn{3}{|c|}{ Areas of current risk } & \multicolumn{3}{|c|}{ Areas of potential risk } \\
\hline & R1 Low & R2 Medium & R3 High & R1 Low & R2 Medium & R3 High & R1 Low & R2 Medium & R3 High \\
\hline Córrego São Miguel & 1 & 6 & 13 & 4 & 2 & 2 & 1 & & 1 \\
\hline COAHB & 1 & 2 & 1 & & & & & 1 & \\
\hline Bom Jesus & & & 3 & & & & & & 1 \\
\hline $\begin{array}{l}\text { Nossa Senhora da } \\
\text { Conceição }\end{array}$ & 1 & 1 & & & & & & & 1 \\
\hline
\end{tabular}
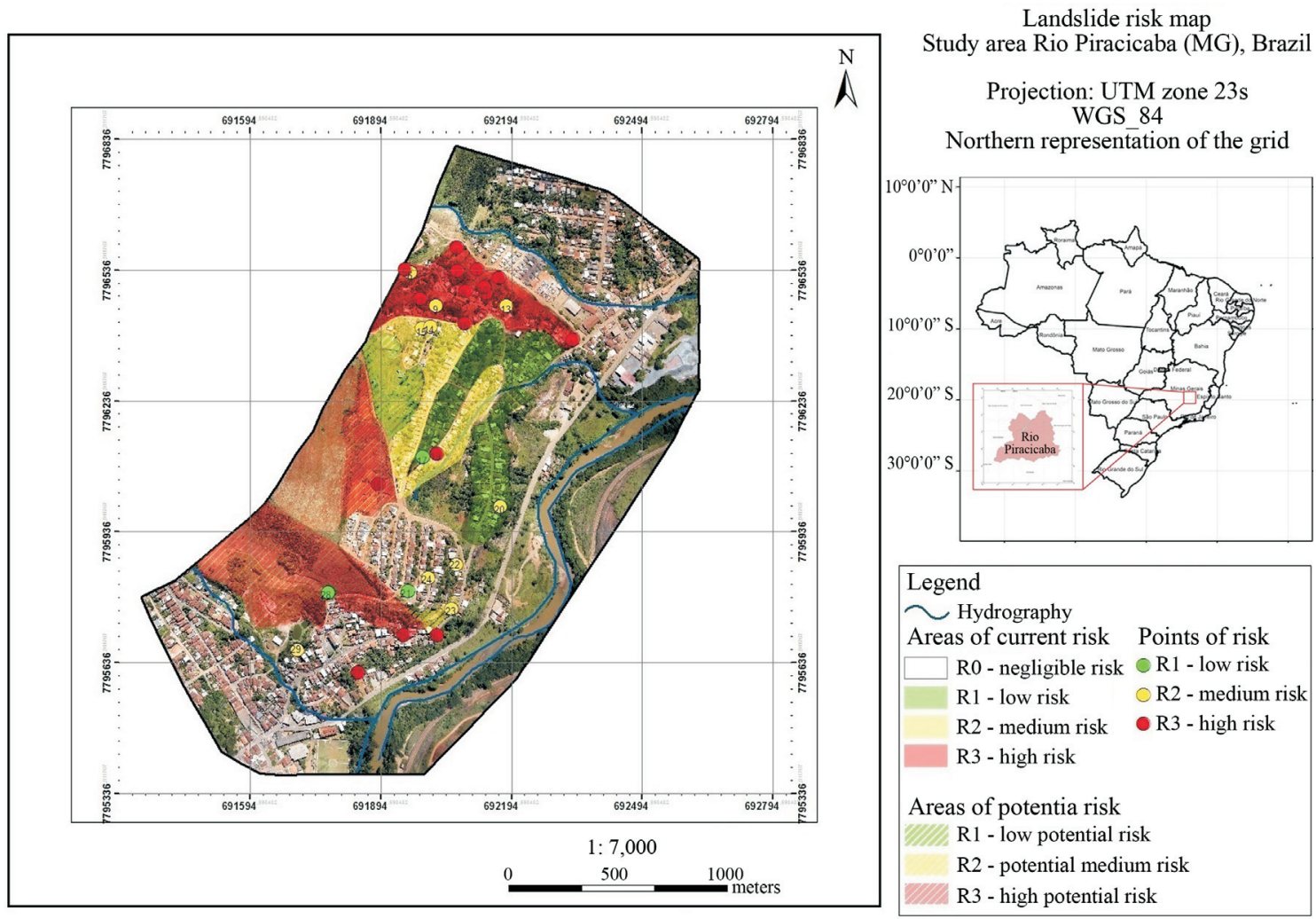

Figure 7 - Landslide risk map: areas of current risk, areas of potential risk (susceptibility) and points of risk - urban perimeter of Rio Piracicaba, MG. 
To elucidate the situation of each neighborhood, the results were subdivided into 4 maps in larger scales, elaborated with the aim of a better representation of the urban and environmental diagnostic of the risk areas.

\subsection{Córrego São Miguel neighborhood}

The anthropic action, as a main environment modifier, in addition to the geotechnical, geological and geomorphological characteristics unfavorable to occupation, have allowed rating Córrego São Miguel neighborhood as the one with the greatest number of identified risk points (20), 8 areas of current risk and 2 of potential risk, which are considered priorities for immediate intervention and restructuring. It is suggested to prevent new occupations and reallocation of the population of the dwellings in the most critical situations and areas (Fig. 8).

The areas classified as high risk (R3) are marked by the presence of precarious and clandestine settlements, located at the top and at the base of cut slopes. There are a series of cuts and embankments carried out in a chaotic manner without any technical supervision, which result in the creation of zones of flow concentration and in large cutting heights and steep slopes. The neighborhood does not even have a sewage collection system and the residual effluents are launched in situ or directed to septic tanks; the drainage systems are non-existent or insufficient, and can

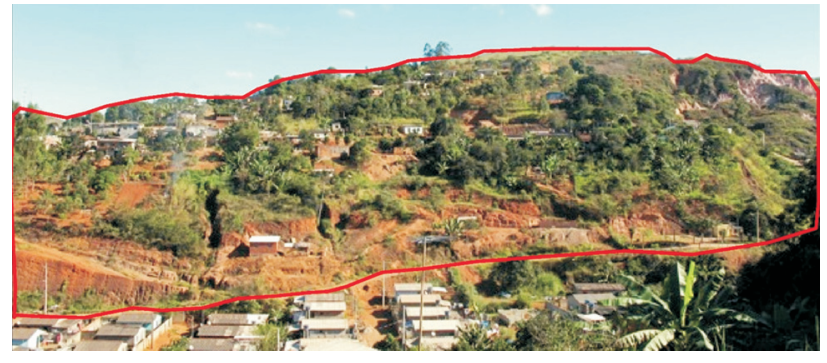

Figure 9 - Delimitation of High-risk points and area in the Córrego São Miguel neighborhood, precarious settlements, absence of rainfall drainage, erosive process in advanced stage and mass movements scars.

increase soil saturation, especially during periods of concentrated and intense rainfall. There are many banana trees whose roots promote water retention, along with dense vegetation on the slope, which may lead to vertical overload. This combination of factors increases the risks of mass movements (Fig. 9).

The predispositions observed in the medium-risk areas and points are related to the presence of exposed young residual soil, with formation of grooves and ravines due to concentrated surface runoff; cracks were also observed in the dwellings. Corrective measures must be taken for these situations, to prevent this degradation stage to progress.

Low-risk points and areas are situated on slopes varying from 3 to $45 \%$, in which the dwellings have better
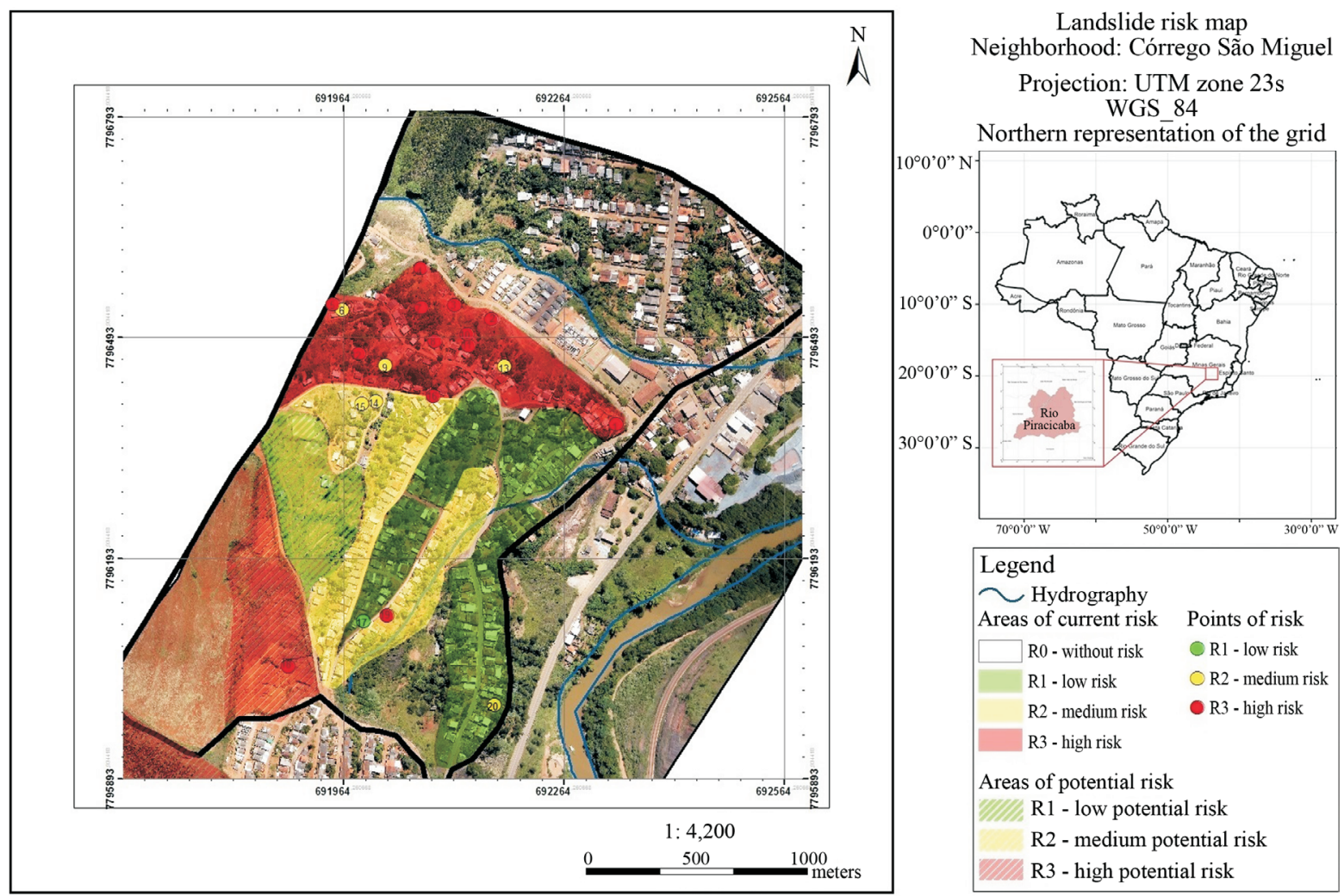

Figure 8 - Landslide risk map of Córrego São Miguel neighborhood, Rio Piracicaba, MG. 
infrastructure conditions. However, damaged wastewater pipes were observed, with the effluents being disposed directly on roads. Although triggeringfactors are incipient, monitoring is necessary. For areas not yet occupied and categorized as with low potential risk, preliminary inspections should be carried out to assess geological-geotechnical characteristics and suitability for urbanization, in order to avoid cluttered occupations and cuts with inappropriate height and excessive slope

The area classified as potentially high-risk and the specified high-risk points described in slope of more than $45 \%$ are related to the exposing of soil and rock and ferruginous soils compounds of strongly erodible lateritic ("cangas"). These materials impose a natural predisposition to morphodynamic deflagrations. It was observed that on erosive processes, the geometry of the slope favors the convergence of flows. According to the Civil Defense, this area has a history of mud runs in periods of heavy rainfall that affects residences located below. The municipality has already promoted some recovery attempts, but none has showed satisfactory results and, currently, the area is protected by wire fences. Occupations should be avoided.

As can be seen in the declivity map with the neighborhood limit (Fig. 10), the diagnosed points of risk are mostly located in the highly hilly terrains. On these points there are shallow soils (mostly silty sand) and rock outcrops in the base of the slopes, which present a natural predisposition for the action of the weather and, consequently, potentiate the risk of mass movements.

\section{2. СОАНВ}

The main risk-inducing factors on COAHB neighborhood are related to slopes with more than $30 \%$ inclination, presence of soil/rock contacts and wastewater being disposed directly on lands and roads. This constant water flow in the soil causes increased saturation, decreases strength so increasing the risk of mass movements. The points classified as low risk require monitoring of the dynamic processes identified, related to the exposed soil and the absence of a drainage system. Drainage works are necessary to solve these problems; as well as planting, to restore the vegetation cover; and containment works, to prevent the degradation to progress (Fig. 11).

The area classified as medium potential risk is located at the base of a slope with inclination higher than $45 \%$ (Fig. 12). The sparse vegetation still acts as a protective layer against water erosion, but the presence of shallow soils can control landslides during heavy rain periods. Thus, it is necessary to monitor the buildings that are located below this slope in order to avoid human and economic losses.

\subsection{Bom Jesus neighborhood}

In Bom Jesus neighborhood, 3 high-risk points were registered. The area demarcated as high potential risk (Fig. 13) corresponds to the face of a mountainous relief
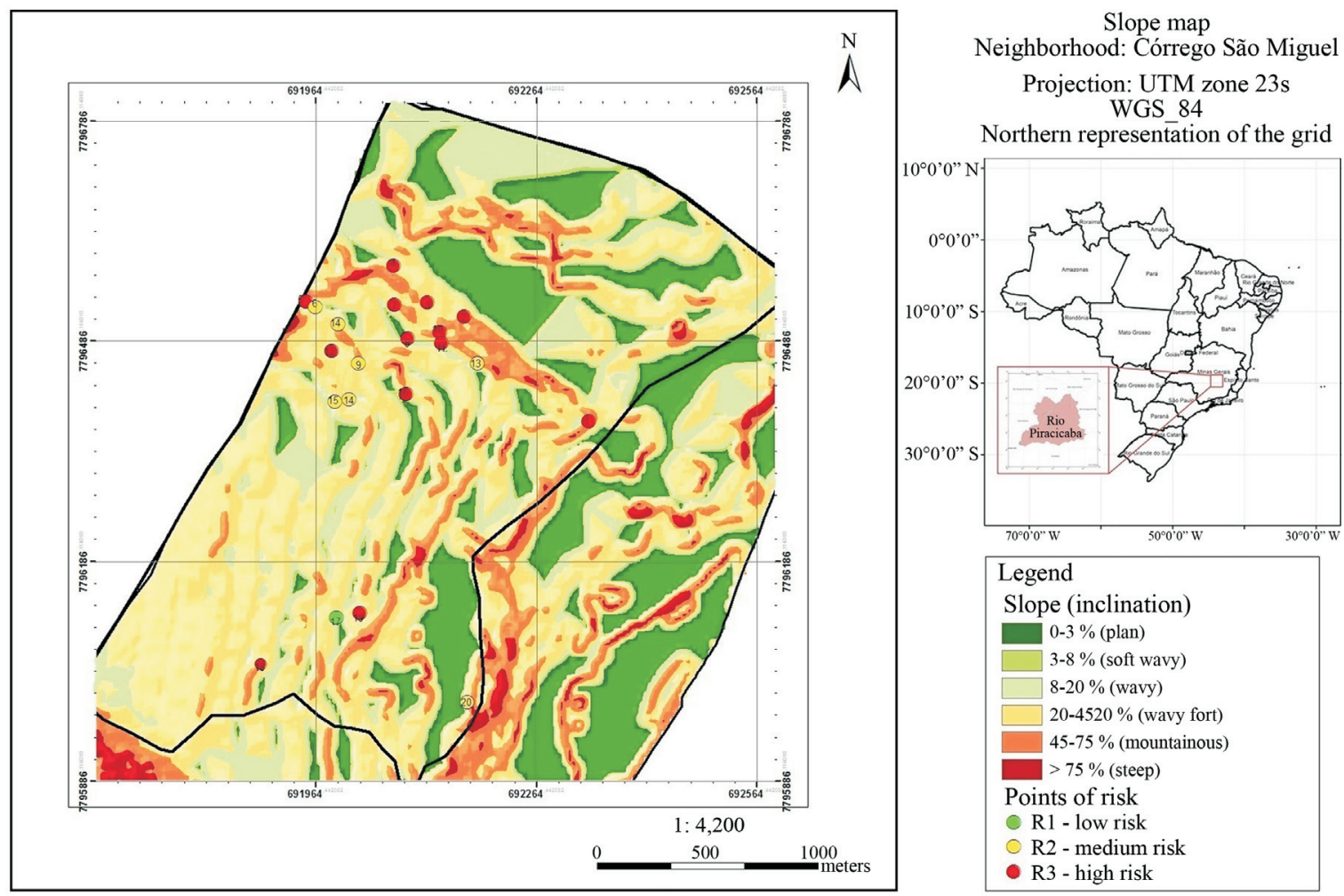

Figure 10 - Slope Map (inclination) (Córrego São Miguel Neighborhood, Rio Piracicaba, MG. 


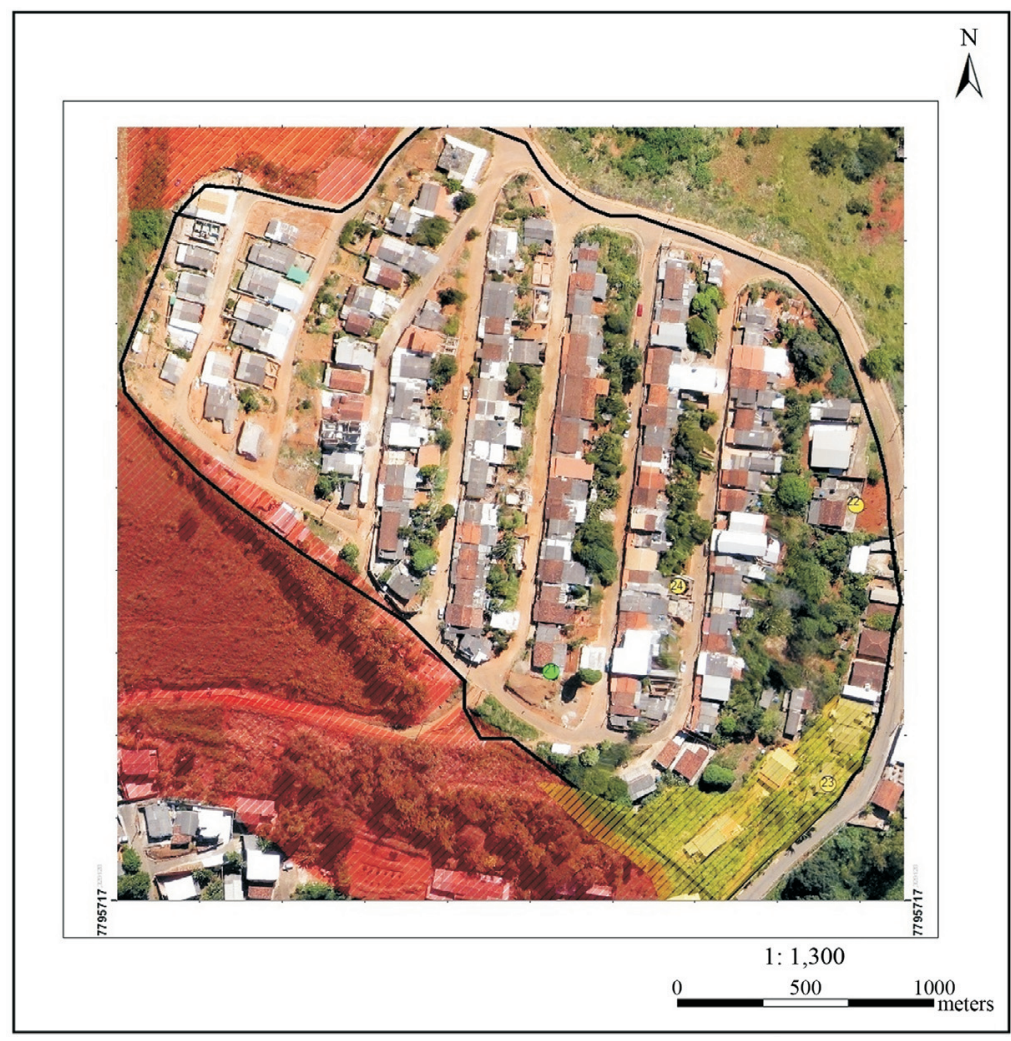

Map of risk to landslide Neighborhood: COAHB P.D.L.V. Barros

Projection: UTM zone 23s WGS 84

Northern representation of the grid

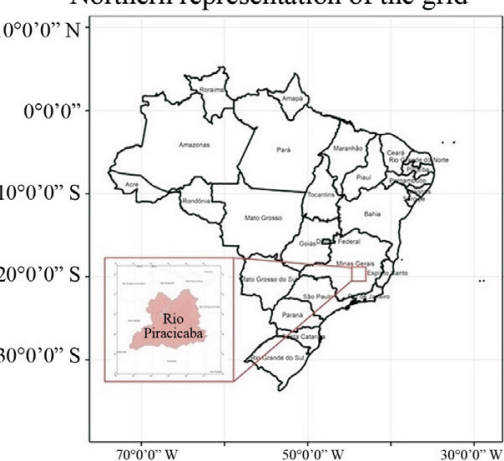

\section{Legend \\ $\mathrm{COHAB}$}

Areas of potential risk

2II R1 - low potential risk

R2 - medium potential risk

VIIIS R3 - high potential risk

Points of risk

R1 - low risk

R2 - medium risk

- R3 - high risk

Figure 11 - Mass-movement risk map (neighborhood) COAHB Padre Levy, Rio Piracicaba, MG.

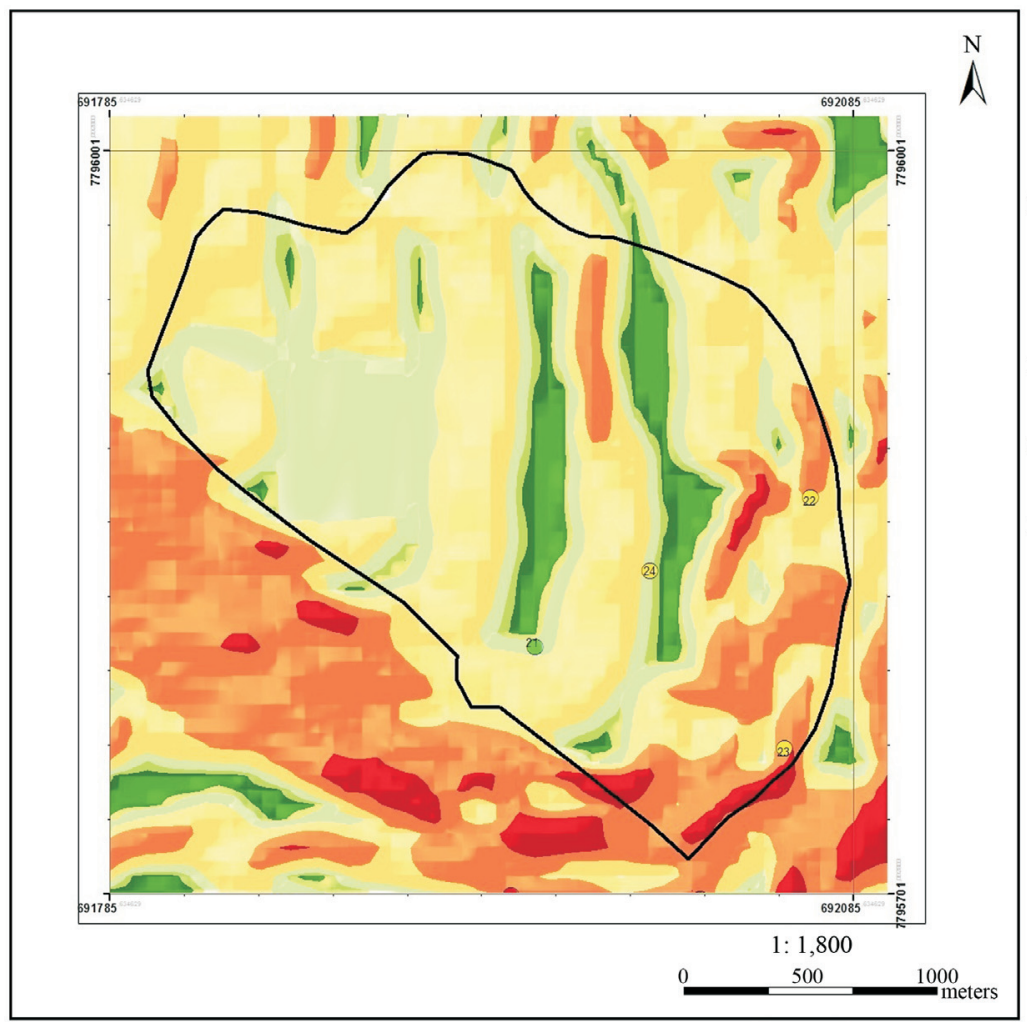

Slope map

Neighborhood: COHAV P.D.L.V. Barros

Projection: UTM zone 23s WGS 84

Northern representation of the grid

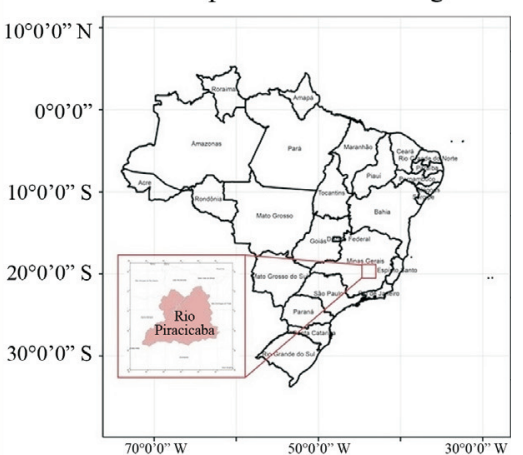

\begin{tabular}{|l|}
\hline Legend \\
Slope (inclination) \\
$0-3 \%$ (plan) \\
$3-8 \%$ (soft wavy) \\
$8-20 \%$ (wavy) \\
$20-4520 \%$ (wavy fort) \\
$45-75 \%$ (mountainous) \\
$>75 \%$ (steep) \\
Points of risk \\
R1 - low risk \\
R2 - medium risk \\
R3 - high risk \\
\hline
\end{tabular}

Figure 12 - Slope (inclination) map of COAHB neighborhood, Rio Piracicaba, MG. 
slope, in which mass movement scars with recomposed crawling vegetation were identified; however, the dwellings below this slope should be monitored.
High-risk points are associated with landslides and presence of housing on the top. Unconsolidated materials and volumes of debris were identified at the talus deposit
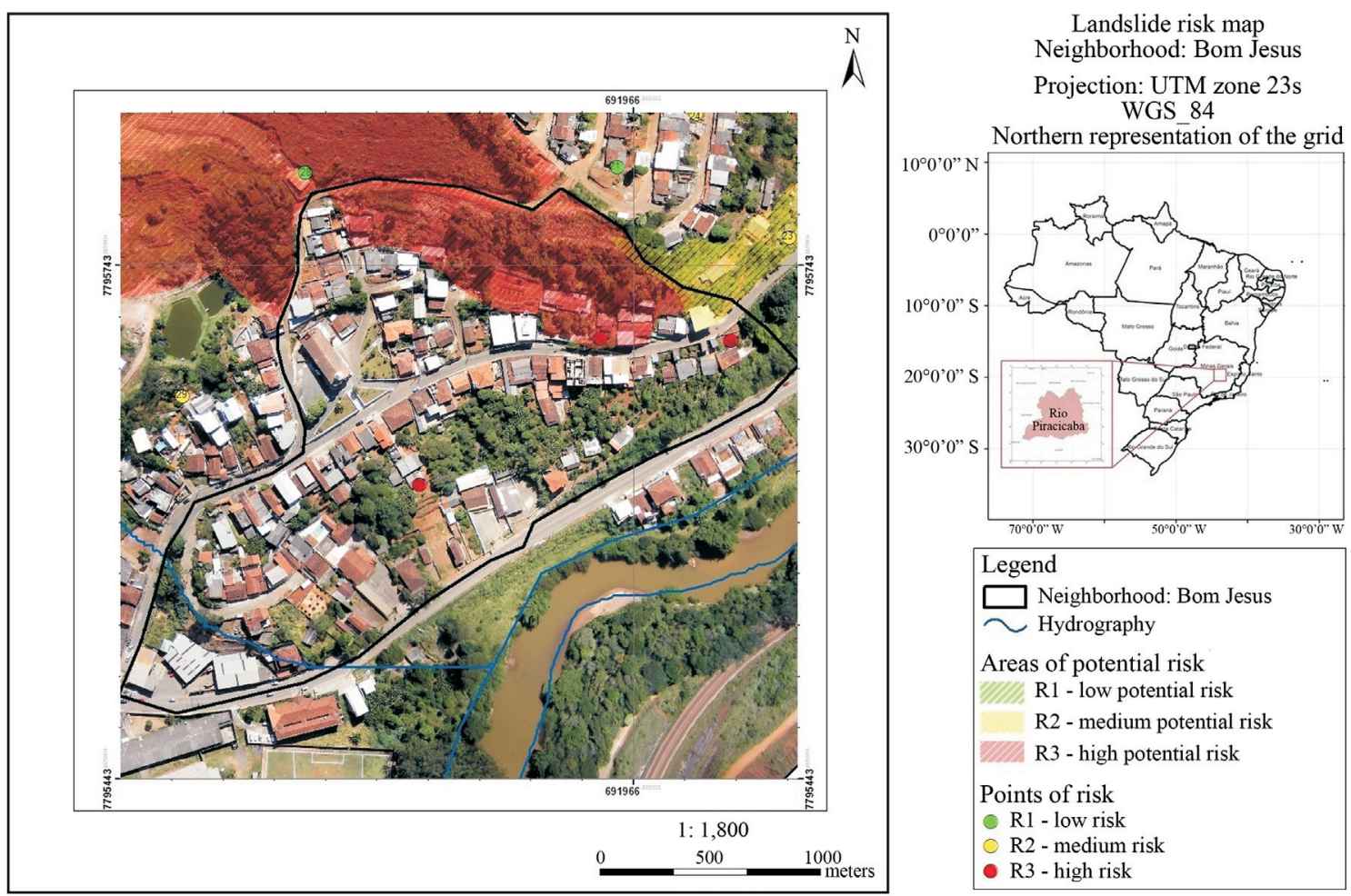

Figure 13 - Mass-movement risk map of Bom Jesus neighborhood, Rio Piracicaba, MG.
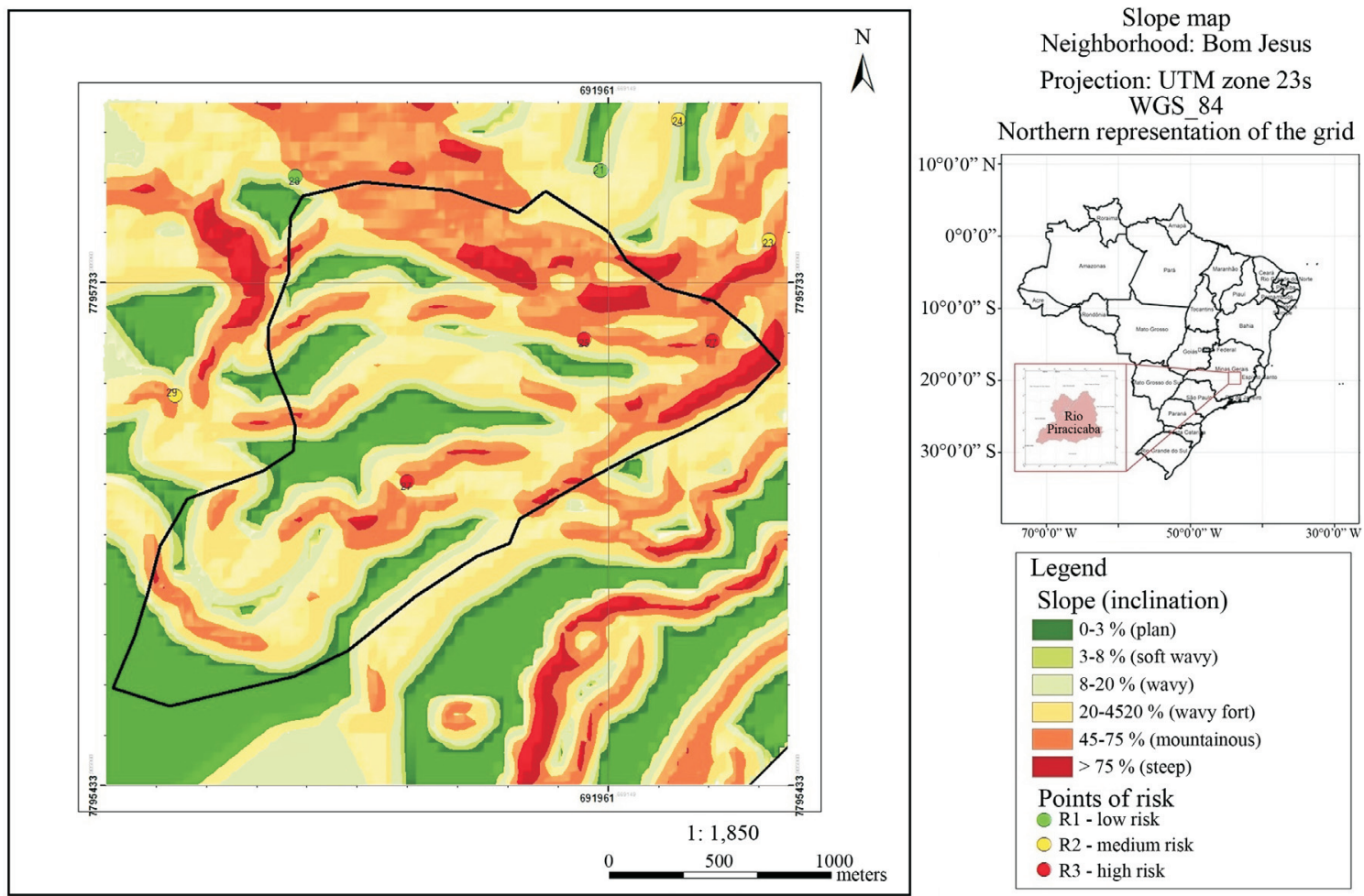

Figure 14 - Slope map (inclination) of Bom Jesus neighborhood, Rio Piracicaba, MG. 
located at the foot of the hillside. Also, features such as apparent mass movements, inefficient retaining wall and absence of drainage increase the risk observed on these points.

These high-risk points must have a solution immediately, probably by a retaining wall. As can be seen in the declivity map (Fig. 14), this neighborhood is mostly located in an area of flat to highly undulating relief and presents a better constructive pattern. However, it should be monitored in order to avoid the emergence of risk-triggering agents.

\subsection{Nossa Senhora da Conceição neighborhood}

The neighborhood of Nossa Senhora da Conceição (Fig. 15) was the neighborhood that appeared to have better conditions of urban planning, despite the insufficiency of existing drainage systems. Only one medium-risk and one low-risk point were identified as presenting predisposing geological-geotechnical conditions. Erosive processes at an early stage of development were observed, as well as old mass-movement scars on a slope $>45 \%$ with poor natural drainage, classified as high potential risk. In the municipality's master plan, these two listed sites are located in an environmental protection zone, which restricts their urban occupation and use, in order to protect and maintain its natural aspect.

According to the declivity map (Fig. 16), the dwellings are mostly located in areas of flat to highly undulating relief.

\section{Conclusion}

Mass movement risk assessment is an indispensable tool for the planning and monitoring of the urban environment and should be incorporated into the instruments of all Brazilian municipalities with the aim of minimizing the disasters caused by this type of event.

After the diagnosis made in the area of study in Rio Piracicaba, MG, it was possible to perceive the inefficiency of legislation and public policies related to the control of land use and occupation within the study area, mainly in the zones of social interest, such as Córrego São Miguel neighborhood.

After classification and integration of the results, it was observed that the points and areas classified as high risk are directly related to anthropic areas on slopes greater than $30 \%$, combined with the presence of dwellings of low constructive standard, with no engineering design, in which population lives in precarious conditions. Furthermore, there is insufficient rainfall drainage system and the disposal of sanitary sewage is absent and/or insufficient. All these aspects, together, intensify the process of soil saturation. In addition, there is a natural predisposition for geoenvironmental problems, such as a rugged topography and the presence of variable lithological units, earthy and rocky substrates of low strength, which are subject to frequent instability processes, by the natural action of gravity and the weather, mainly in periods of rainfall concentration. In this context, in which the risk scenario is imminent in relation to
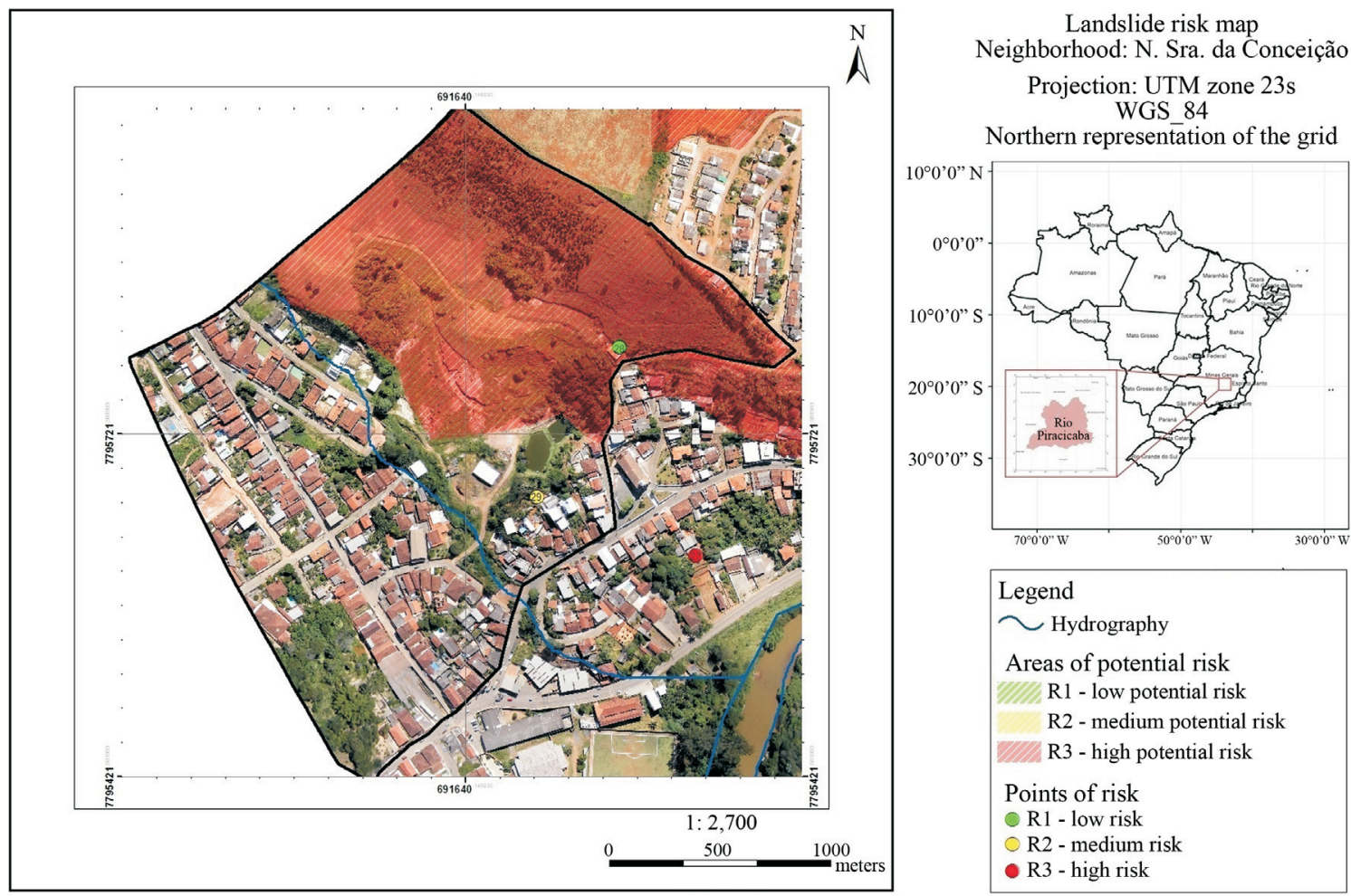

Figure 15 - Landslide risk map, Nossa Senhora da Conceição neighborhood, Rio Piracicaba, MG. 

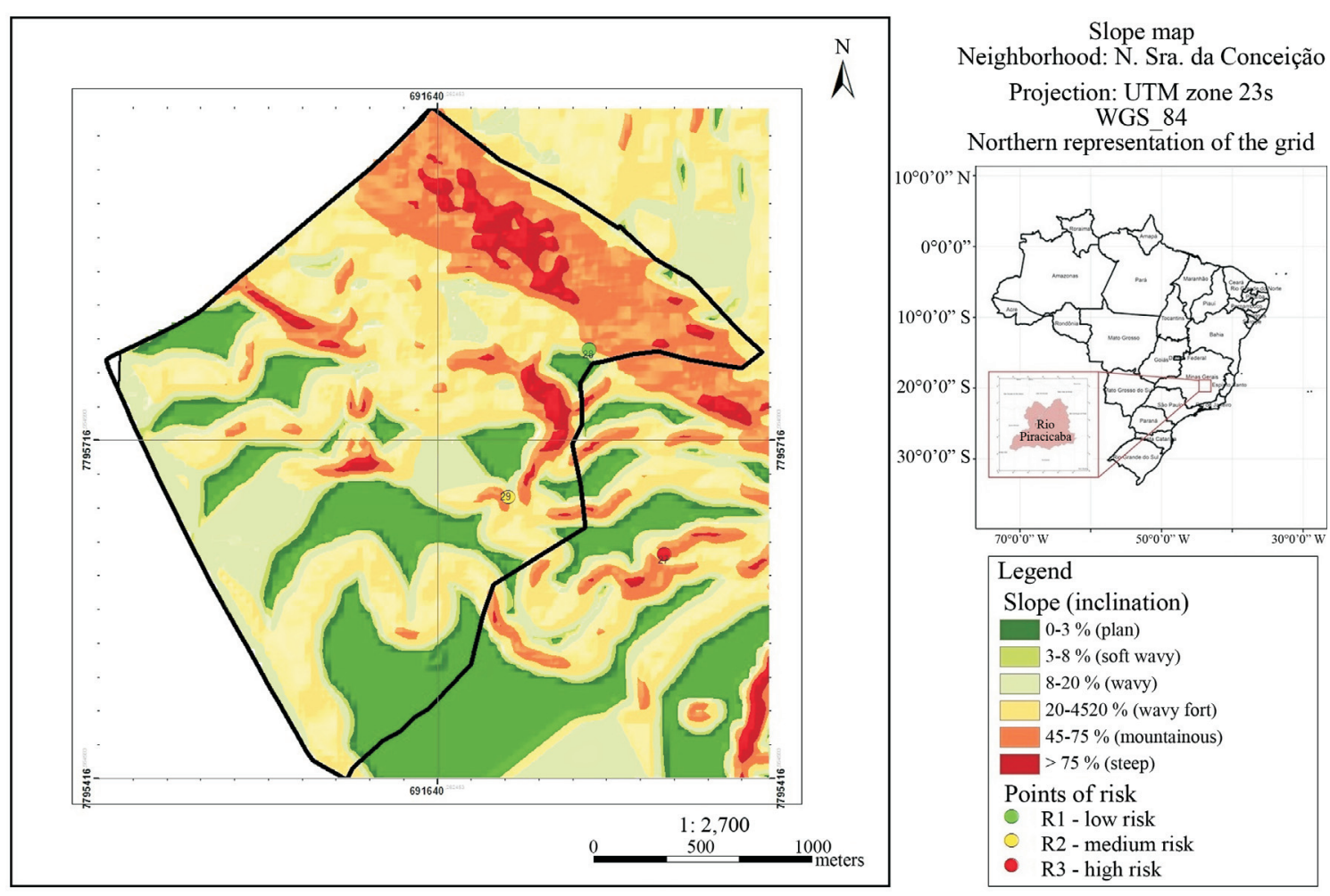

Figure 16 - Slope map (inclination) Nossa Senhora da Conceição neighborhood, Rio Piracicaba, MG.

the integration of the natural environment and the built environment, immediate interventions must be made by the Civil Defense, starting by withdrawing and relocating those dwellers in the most precarious situations, carrying out stabilization works, and promoting sustainable actions and educational activities to raise awareness within the population about the risks they are exposed to, so as to increase awareness and discipline to prevent future accidents.

The procedures used in this work through the application of the methodology of the Ministry of Cities have shown that, despite being considered a subjective evaluation by several authors, it is a low-cost process, effective as a preliminary identification of the main predisposing geological-geotechnical destabilization mechanisms. However, it is important to emphasize the importance of having professionals with experience and technical capacity to perform interpretations in the field, in order to coherently rank the risk level. It is worth stressing the need for these mappings to be updated annually, with the purpose of verifying the evolution of the risk frameworks in the municipality.

The use of the post-processing orthorectified image obtained from the survey of the Unmanned Aerial Vehicle-UAV, allowed the preparation of current maps with visual quality in detail scales, which ranged from 1:7.000 to $1: 800$, contributing to the integration of the data in the GIS environment. It can, therefore, be considered an excellent resource for obtaining, classifying, vectoring and plotting the specific areas of interest, besides being a suitable and agile support for geological-geotechnical mapping works.
Thus, it may be of help for other projects involving environmental planning of the municipality.

\section{Acknowledgments}

To Brazil's CAPES Agency for the financial support, and to Civil Engineering Department of the Federal University of Viçosa and the Federal Rural University of Rio de Janeiro for technical support.

\section{References}

Akgun, A. (2012). A comparison of landslide susceptibility maps produced by logistic regression, multicriteria decision, and likelihood ratio methods: a case study at Izmir. Turk Landslides 9(1):93-106.

Araújo, P.C. de. (2004). Susceptibility Analysis to Landslides: A Probabilistic Approach. Doctoral Thesis in Geociências e Meio Ambiente, Instituto de Geociências e Exatas, UNESP, Rio Claro, 172 p (in Portuguese).

Bigarella, J.J. \& Passos, E. (2003). Structure and Origin of Tropical and Subtropical Landscapes, v. 3. Editora da UFSC, Florianópolis (in Portuguese).

Brasil (2001). Law 10.257 (July 10th, 2001). Establishes general guidelines for urban policy and define other actions. Congresso Nacional, Brasília (in Portuguese).

Brazil (2001). City Statute Guide for Implementation by Municipalities and Citizens. Congresso Nacional, Brasilia, 273 p. (in Portuguese). 
Brazil (2007). Ministry of Cities. Risk Mapping on Slopes and River Banks. Carvalho, S.C.; Macedo, S.E. \& Ogura, T.A. (orgs). Instituto de Pesquisas Tecnológicas, Brasilia, Available in: http://www.cidades.gov.br/ (in Portuguese).

Brasi (2012). 1. Law 12.608 (April 10th, 2012). Establishes the National Protection and Civil Defense System SINPDEC and the National Council of Protection and Civil Defense - CONPDEC. Diário Oficial da República Federativa do Brasil, Brasília (in Portuguese).

CETEC (1983). Technological Center Foundation of Minas Gerais. Environmental Diagnosis of the State of Minas Gerais, Belo Horizonte, 148 p (in Portuguese).

CPRM (2010). Brazilian Pluviometric Atlas. CPRM - Mineral Resources Research Company Available in: http://www.cprm.gov.br (in Portuguese).

CPRM (2014). Emergency Action for Delimitation of Areas at High and Very High Risk to Floods and Mass Movements Rio Piracicaba - Minas Gerais. Rio Piracicaba, Minas Gerais, Brazil. CPRM - Mineral Resources Research Company. Available in: http://www.cprm.gov.br/publique/Gestao-Territorial/ Geologia-de- Engenharia-e-RiscosGeológicos/Setorização-de-Riscos-Geológicos 4138.html\#minasgerais (in Portuguese).

Diniz, N.C. (2012). Cartografia geotécnica por classificação de unidades de terreno e avaliação de suscetibilidade e aptidão. Revista Brasileira de Geologia de Engenharia e Ambiental, 2(2):29-78.

EMBRAPA. (1979). National Land Survey and Conservation Service. EMBRAPA - Brazilian Agricultural Research Agency In: $10^{\text {th }}$ Technical Land Survey Meeting, Rio de Janeiro. Proc. Rio de Janeiro, 83 p (in Portuguese).

IBGE. (2010). 2010 Census. IBGE - Brazilian Institute of Geography and Statistics. Available in: http://www.ibge.gov.br/home/ estatistica/população/censo2010/default.shtm (in Portuguese).

IPT. (2015). Bitar, O.Y. (org.) Geotechnical Charts Guide: Basic Guidelines for Municipalities. Instituto de Pesquisa tecnológica do Estado de São Paulo. Available in: www.ipt.br/guia_cartas_geotecnicas.pdf (in Portuguese).

Marchiori-Faria, D.G.; Ferreira, C.J.; Rossini-Penteado, D.; Fernandes-da-Silva, P.C. \& Cripps, J.C. (2005). Mapping of landslide and flood risk areas in housing areas of Diadema, SP. In: Annals XI Brazilian Congress of Engineering Geology, 2005, Florianópolis. ABGE, Florianópolis, CD-ROM (in Portuguese).
Marques, J.A.P.; Souza, J.H. \& Maragon, M.A. (2011). Interference of landslides in traffic interruption in urban public roads in the city of Juiz de Fora - MG. In: 17th Urban Paving Meeting. Porto Alegre, RS. Anais. ABPV, Rio de Janeiro CD-ROM (in Portuguese).

Roque, L.A. (2013) Geological-Geotechnical Risk Areas Associated with Mass Movements in the Urban Core of Viçosa-MG. Master's Thesis em Engenharia Civil, Universidade Federal de Viçosa, Viçosa, 110 p (in Portuguese).

Saito, S.M.; Soriano, E. \& Londe, L.R. (2015). Natural Disasters/Remote Sensing for Disasters. Oficina de Texto, São Paulo, 285 p (in Portuguese).

Shahabi, H. \& Hashim, M. (2015). Landslide susceptibility mapping using GIS-based statistical models and Remote sensing data in tropical environment. Sci Rep 5:9899. doi:10.1038/srep09899.

Santiago \& Cintra available in: https://www.santiagoecintra.com.br/.

Souza, L.A. (2015). Geoenvironmental Cartography and Progressive Geotechnical Cartography at Different Scales: Application in the Ribeirão do Carmo Watershed, Municipalities of Ouro Preto and Mariana, Minas Gerais. Doctoral Thesis, Escola de Minas, Universidade Federal de Ouro Preto, Ouro Preto, 456 p (in Portuguese).

Tominaga, L.K. (2007). The Evaluation of Different Methods Employed in Landslide Risk Analysis: The Application of a Methodological Proposal in Ubatuba, SP. Doctoral Thesis in Sciences, Physical Geography, Faculdade de Filosofia, Letras e Ciências Humanas, da Universidade de São Paulo, São Paulo, 240 p (in Portuguese).

UNISDR (2004). Living whit Risk. A Global Review of Disaster Reduction Initiatives. UNISDR United Nations International Strategy for Disaster Reduction. United Nations ISDR, Geneva, Switzerland.

UNISDR (2009). Terminology on Disaster Risk Reduction. UNISDR - United Nations International Strategy for Disaster Reduction. United Nations Strategy for Disaster Reduction, Geneva, Switzerland.

Vieira, V. (2000). Preliminary Characterization of the Geological Risk of the Urban Area of Viçosa - MG. Master's Thesis em Engenharia Civil, Universidade Federal de Viçosa. Viçosa, Minas Gerais, 92 p (in Portuguese).

Wolle, C.M. (1988). Analysis of Translational Landslides in the Serra do Mar in the Context of a Classification of Mechanisms of Slope Instability. Doctoral Thesis em Engenharia, Escola Politécnica, Universidade de São Paulo. São Paulo, 394 p (in Portuguese). 